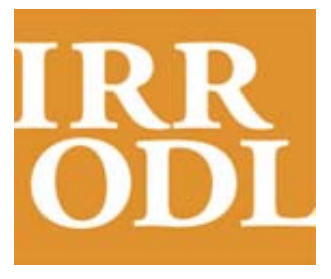

International

Review of

Research in Open

and Distance

Learning

Vol. 12.2

February - 2011

\section{The Isolation of Online Adjunct Faculty and its Impact on their Performance}

\author{
Véra Dolan \\ DePaul University and Ellis University, USA
}

\begin{abstract}
Using a grounded theory qualitative research approach, this article examines the experiences of 28 adjunct faculty members who work at the same university, exploring their views on whether periodically meeting face-to-face with management and peers has the potential to affect their motivation on the job and consequently the quality of education they provide to students. A few management representatives also shared their perspectives on the phenomenon; this enabled the researcher to compare the views of these two populations on whether face-to-face contact among faculty enhances teaching performance. The results of this study suggest a few issues that online schools must address in their efforts to improve adjuncts' sense of affiliation and loyalty to their institution, which in turn will positively affect student retention levels. The main issues of concern to adjunct faculty are (a) inadequate frequency and depth of communication, regardless of the means used, whether online or face-to-face; (b) lack of recognition of instructors' value to the institution; and (c) lack of opportunities for skill development.
\end{abstract}

Keywords: Adjunct faculty; affiliation; isolation; loyalty; organizational commitment; psychological isolation; sense of community; social capital; trust 


\section{Introduction}

A growing number of US workers are telecommuters who perform their jobs remotely most days of the week. Among these millions of virtual workers are many online educators, particularly adjunct instructors who teach for distance education institutions across North America and in other parts of the world.

Academic administrators, increasingly aware of the potential alienation that physical distance can cause, have looked for ways to create a greater sense of community among online adjunct faculty members. The rationale for their efforts is based on the hope that online faculty will exchange best practices, thereby improving both their skills and their motivation; this ideally will enable schools to retain students because superior services are provided by motivated faculty members. However, educational administrators often appear to concentrate solely on the accomplishment of tasks, disregarding the importance of nurturing relational, social, and personal ties with telecommuting staff.

Many administrators who oversee virtual faculty apparently believe that with advanced technology they can create dialogue, knowledge exchange, and collaboration, which in their minds should be sufficient to cultivate loyalty among instructors. However, in order to encourage the best possible performance from remote workers, it is essential for educational institutions to understand that regardless of how sophisticated technology may be in opening communications channels, it cannot create a totally fulfilling work experience (Helms \& Raiszadeh, 2002). The mere existence of a virtual academic community does not necessarily foster faculty loyalty toward management and the institution.

Administrators, for their part, cannot be sure that a technology-based community of practice will provide reliable indicators of mutual trust. In any sector, a significant part of employees' motivation to be strong performers, regardless of the nature of their work, comes from a sense of affiliation with their organization and from the feeling that they are trusted and personally valued by their employers. In higher education, motivated faculty are more likely to strive in their teaching and research if they have a strong sense of belonging to the institution and feel connected to the student body. Fukuyama (1995) defends the idea that reciprocal trust can only emerge within a social context in which virtues such as honesty, reliability, cooperation and a sense of duty to others becomes palpable: "Although there may be some countervailing trends in the newer networking technologies, it remains to be seen whether virtual communities will be an adequate substitute for face-to-face ones” (p. 317). In addition, when people place trust in colleagues and administrators according to "a common set of norms" (p. 27), operational costs decrease. Fouche (2006) asserts that if feelings of isolation are reduced, faculty retention is likely to rise, which means that the university will retain the precious knowledge and skills of good workers. This is important to keep employee turnover rates down and to minimize the need to constantly hire inexperienced instructors, which can entail significant added costs for recruitment, training, and coaching, as well as for additional course materials.

If we accept these added costs as a given, we can conclude that it is critical for the administrators 
of online educational institutions in their ongoing pursuit of higher student retention rates to gain insights into how they can better nurture loyalty and enthusiasm among faculty, particularly in an environment that can easily be perceived as cold and impersonal. Indeed, Roberts, Thomas, McFadden, and Jacobs (2006) point out that a key question to keep in mind with regard to the motivation of adjuncts is how the work of faculty learning communities affects student retention. If instructors do not feel positively connected to their peers and school management, their commitment to the team, including their determination to "not let people down," will be negligible, perhaps even nonexistent. As a result, these faculty members will not put much energy into performing well, which cannot help but affect their students' learning processes significantly. In an online educational environment, it is not uncommon for students to lose momentum due to their lack of proximity with others. If instructors are not willing to be supportive and help such students get back on track, feelings of isolation will put their overall performance at risk, and dropout rates are likely to increase.

Another crucial question, given the difficulty of building strong emotional bridges with virtual staff, is whether periodically gathering remote instructors for face-to-face meetings will encourage stronger relationships and deepen their sense of commitment to the institution. It is just as important to ask whether bringing adjunct faculty together will deliver a better educational experience to students. Finally, in situations where meeting face-to-face on a regular basis is difficult, the challenge for academic managers is to determine how often they should create opportunities for remote faculty to mingle with peers and management in a social context, or, if this is not possible, to decide how they can achieve the same goals from a distance.

\section{Purpose of the Study}

A qualitative study was performed to explore the overall perceptions held by online adjunct instructors regarding the efforts of their academic institution to establish a relationship based on trust, loyalty, sense of affiliation, and commitment to high-quality services. The aim of the study was to explore whether periodically meeting face-to-face would nurture a stronger personal connection between academic management and faculty, a connection in which adjunct instructors' psychological and social needs would be respected, motivating them, in turn, to provide students with the best possible learning experience. Therefore the key question in this proposed study, posed to both management and adjunct faculty, focused on uncovering strategies the institution could use to foster a stronger relationship with adjunct faculty:

Can periodic face-to-face contact create a more significant social and personal bond between management and online adjunct faculty, instilling in instructors a stronger sense of pride and loyalty that will enhance their performance and potentially increase student retention rates? 


\section{Significance of the Study}

This study sought to examine how the sense of isolation from management and peers experienced by instructors teaching remotely might affect their level of motivation and consequently their job performance in the online education environment. It was hoped that the study's findings could help shed light on social desires and needs which if met by the institutions with which these individuals were affiliated would have a significant positive impact on their loyalty, pride, and commitment. At a time when the competition for online students has become fierce, it is vitally important for distance education administrators to extend the best possible treatment to adjunct faculty. Clearly defined and strong incentives for instructors to remain with the organization help build and maintain a positive experience for both current and potential students.

\section{Delimitations}

This study was conducted solely with adjunct instructors and members of the academic administration who were active at the university at the time they were interviewed. Many instructors had direct relationships with the researcher, who had trained and coached them at some point during their contract work with the school. However, other instructors were also invited to participate in the study. The researcher also interviewed management staff in order to gain their perspective on the school's success in nurturing loyalty and commitment among faculty members.

\section{Literature Review}

Although there is growing recognition of the value that part-time and adjunct faculty bring to academic institutions, the drive to create a greater sense of community still faces significant practical obstacles. In 2003 adjunct instructors accounted for 65\% of the workforce in education, according to a US Department of Education report (Abowd, 2008). Brewster points out that these instructors cost less than full-time faculty; moreover, they typically do not receive benefits such as health insurance, sick days, or vacation time (as cited in Gordon, 2003, p. 3). McGuire (1993) rationalizes this practice by saying that hiring adjuncts is an important strategy for saving money and maintaining flexibility. However, it can be difficult, if not impossible, to reconcile the pursuit of cost efficiency with a commitment to being more sensitive to instructors' needs.

Beyond the inequities of compensation, these instructors are often treated as outcasts by the academic mainstream. Adjuncts have been referred to by Smith (as cited in Gordon, 2003, p. 1) as a "sort of migrant underclass in academia." They are accused of degrading "academic quality and integrity of the institution, because their teaching skills are inferior to full-time faculty" (Gordon, 2003, p. 4). Adjunct faculty members are also variously known as academic gypsies, highway fliers, and "roads scholars," among other epithets (Ludlow, 1998, p. 52).

According to Unger (1995), "putting an end to the unethical exploitation of part-time faculty members demands a moral awakening” (p. 61). Academic institutions must understand that, in 
light of the growing number of adjuncts, the integrity and success of many schools will depend on these instructors, which means they must be given the respect they deserve. Not only is this a moral requirement, but it is also a shrewd "business" strategy.

Despite this recognition that attitudes need to change, widespread disenchantment among adjunct instructors remains a problem: "[A] large proportion of universally dissatisfied part-time faculty will likely have a pervasively negative impact on the quality of education throughout higher education” (Gordon, 2003, p. 6). If this statement proves to be true, it is likely that student retention will be negatively affected.

In their quest to deliver quality distance education, many institutions are struggling to define strategies for creating trust and loyalty in their adjuncts. Isolation resulting from physical distance seems to be a huge obstacle for nurturing meaningful, rewarding, and personalized relationships. Feelings of disconnection from issues and policies affecting students, as well as from the overall organizational culture, appear to impede efforts in training and development, along with coaching. The effort required to bridge the gap between management and faculty is considerable, particularly when the bulk of research on this subject has been conducted outside the halls of higher education, which leaves school administrators yearning for more promising insights.

Although more research needs to be conducted in the academic field, it is not unreasonable to assume that many phenomena experienced in the business world could exist in distance education as well. According to Merriman, Schmidt, and Dunlap-Hinkler (2007), "leaders who fail to recognize and adapt to these differences risk alienating a growing segment of the overall virtual workforce” (p. 6). Limited opportunities for personal interaction appear to be detrimental to morale, which leads to poor performance and a lower quality of service delivered to customers. Research has demonstrated a correlation between frequency of communication and interpersonal trust, organizational commitment, and a sense of affiliation with the organization (Marshall, Michaels, \& Mulki, 2007). In order for individuals to see the value of organizational membership, a high level of contact is required between management and employees, as well as between employees and their peers. Quite simply, building a relationship grounded in mutual trust is extremely difficult to accomplish at a distance (Morgan \& Symon, 2002), so much so that some organizations are rethinking telecommuting policies and recalling many employees to traditional offices in the belief that "teamwork improves when people work face-to-face" (Shellenbarger, 2008).

Cummings, Heeks, and Huysman (2008) attempt to explain why organizations believe in providing their teleworkers with sophisticated technology to communicate with peers and management by stating that "[t]he facility to create dialogue, learning and collaboration among these [virtual] groups [...] makes these networks a very attractive proposition” for employers (p. 573). However, the creation of virtual spaces that allow communities of practice to interact does not necessarily translate into social interaction nor does it guarantee the development of emotional ties among members or between members and the sponsoring organization. In a world where many people spend much of their lives working and interacting with bosses, subordinates, and colleagues, it is natural that they also develop a stronger need for friendships based on trust 
and reciprocity in the workplace. Putnam (2000) contends that "many studies have shown that social connections with co-workers are a strong predictor-some would say the strongest single predictor—of job satisfaction” (p. 90).

It is not uncommon to encounter feelings of frustration in the absence of the social cues that occur in a face-to-face environment. This has an impact on motivation, trust, reciprocity, and ultimately job satisfaction with many remote employees citing plans to leave their jobs or at least expressing a lack of interest in organizational outcomes. "With high level of social capital, people are motivated, and are both able to and have the opportunity to share knowledge with each other in a network” (Cummings et al., 2008, p. 582). If face-to-face interaction is limited or nonexistent, trust cannot be developed (Bergum, 2007). And only by gaining trust in workplace relationships, suggest Edwards and Sheperd (2007), will workers be inclined to take part in organizational civic participation and engage in a spirit of volunteerism that promotes actions aimed at the common good.

In light of these findings, while keeping in mind that there has not been much research conducted in the academic sector to better guide administrators, some have argued in favor of gathering virtual instructors together from time to time. Golden (2006) asserts that managers should organize face-to-face activities with their telecommuting workers in order to strengthen socioemotional bonds within the organization. If meeting in person is not possible, management must find ways to create a personalized rapport with each virtual worker and to foster conditions in which social exchanges among remote employees can occur more frequently. Brignall III and Van Valey (2005) stress that computer-mediated communication (CMC) is not the problem per se; the key lies in determining how to make use of this tool in order to bond socially with telecommuters. The importance of creating situations that facilitate casual interactions, friendship, and camaraderie must not be underestimated (Marshall et al., 2007).

\section{Methodology}

This study employed a qualitative inquiry approach in order to understand the cognitive processes of instructors and management as they applied meaning to concepts such as trust, loyalty, and motivation in the workplace. Because the intention was to move from rigorous observation to abstract generalization, the path chosen was a grounded theory inquiry. The researcher developed a systematic set of procedures to inductively derive a theory about the experiences of members of the university community. Using the code system of gathering data, she looked for common themes and patterns of meaning in subjects' responses then developed interpretations that plausibly accounted for the information gathered. The core variable, that is, a sense of isolation on the part of adjunct faculty, was the focal issue, assumed to be alleviated by face-to-face meetings. This, in turn, would potentially lead instructors to feel a deeper sense of loyalty to the institution as well as to students. Using the constant comparative method to contrast the content of all interviews, the researcher tried, as much as possible, not to bring her own biases into the matters being discussed; instead, she compared the opinions expressed by those who were interviewed, without stopping to reflect on whether she agreed or not with what was being said. She then offered hypotheses about the isolation and alienation experienced by adjuncts, along 
with ideas on how to reduce that alienation. Asking open-ended questions and giving respondents time to talk about their experiences was deemed the most effective way to gain a significant amount of information and from there to understand adjuncts' stories and analyze their possible meanings.

Given that a significant number of the instructors were invited to participate in this research, the investigator expected that many would respond and, moreover, that the findings could be representative of what other institutions experience, particularly considering that most of the instructors work for other institutions as well. That said, the analysis of results invited future research. This inquiry, therefore, had two main aims: (1) to understand the needs of virtual instructors and the views of university management using a qualitative methodology, and (2) to authenticate the findings and inspire the school's administrators to introduce effective changes within the university.

Sample size in this grounded theory study was not predetermined. As the study proceeded, the researcher chose to continue gathering samples until no new patterns and codes emerged, that is, until the data achieved a level of theoretical saturation. In practice, this meant that the researcher needed to interview more than 20 individuals (Thomson, n.d; Morse, 2000).

While securing agreements from many instructors to participate in the study, the researcher presented her proposal to university management so she could gain their insights as well, making this a participatory study in which the findings would later be discussed with all of the interested parties.

In order to become a respondent, an instructor had to fulfill two criteria: (1) he or she was a current adjunct faculty member; and (2) he or she was willing to answer an open-ended questionnaire and later talk on the telephone with the researcher. A member of the university's administrative staff provided the researcher with a complete list of current adjunct faculty members in all academic departments. Respondents were chosen at random, their names drawn blindly from a bag.

Participants were asked to respond to an emailed questionnaire. This was followed by a telephone conversation to collect additional details. A questionnaire was also sent to all individuals in management positions with the goal of having as many perspectives from university leaders as possible.

\section{Data Analysis Procedures}

The first step in the data analysis was to look at each completed questionnaire as well as the notes from the telephone interviews in order to obtain a general sense of the messages conveyed in each medium. Categories were defined in terms of significant phenomena that pointed to adjuncts' main concerns: 
1. problems in general, such as worrisome issues with regard to the school's current administrative approach;

2. communication problems, such as flaws in the way the university management keeps adjuncts informed (or their failure to do so);

3. motivators, for example, what keeps instructors enthusiastic about teaching;

4. positive aspects of communication, such as the helpful features of the channels routinely used by the university for the exchange of information;

5. praise, a collection of statements commending the university on different aspects of its management and processes;

6. general suggestions, a compilation of ideas for creating an improved and more motivating work environment;

7. suggestions for face-to-face (F2F) interaction, for example, proposals focused specifically on what adjunct faculty would like to see and do if offered opportunities to meet face-to-face; and lastly,

8. impact, the effect that face-to-face meetings have on adjunct faculty members, particularly with respect to their motivation and loyalty to the institution.

\section{Results}

Many respondents were candid with regard to issues that were a source of frustration for them. Some expressed their dissatisfaction passionately; others welcomed the opportunity to express their views in person (via telephone interview). Although some were more emphatic than others in expressing their unhappiness with aspects of teaching for the university, certain topics were repeated frequently, forming a pattern that led to the creation of subcategories for the category in question.

A number of adjuncts took the opportunity to express their unhappiness regarding their compensation. The practice of offering low pay to adjuncts is not uncommon. Virtual schools can hire instructors from anywhere in the world "without paying the significantly higher cost of an equally qualified full-time faculty” (Gaillard-Kenney, 2006, p.10). Anderson (2002) confirms this when discussing the exploitation of nontraditional faculty by colleges that pay "a fraction of what the same course would cost if taught by a full-time faculty member” (p. 2). When pay is perceived as not enough, many instructors appear to look for other forms of compensation, and a sense of affiliation with the school they work for could be a fundamental factor for their satisfaction at work.

Another constant topic was the sense of disconnection experienced by these adjuncts. This is supported by Schnitzer and Crosby (2003), who observe that “[d]istance learning adjuncts, especially those who are physically removed, are particularly vulnerable to feeling disconnected from the institutional environment" (Orientation and Training section, I 1). Some of the comments from faculty members also illustrate a problem raised by Yu and Young (2008), that "online interaction strips away many of the social cues intrinsic to face-to-face interaction, leading to confusion among group members” (p. 88). If communication is deficient, engagement in cooperative behavior and organizational identification is compromised. 
Many adjuncts reported that they did not feel they belonged to the organization they worked for. A large number did not see themselves as part of a team working with a common vision and goal. According to Nelson (2002), among the obstacles impeding success in virtual organizations, three are of critical importance: “a) people lose interaction with managers and co-workers; b) the ability to participate and contribute to a work team is more difficult; and c) the company culture and sense of bonding around common values of purpose can slowly erode” (p. 1). Therefore, the potential value of frequent and clear communication throughout a virtual academic organization should not be underestimated.

Feeling unvalued and taken for granted was another issue for adjunct instructors. Many expressed unhappiness arising from the perception that the university did not recognize them as a source of valuable knowledge and help. For these participants, there was a perceived failure by management to request instructors' input on matters of academic concern. Moreover, many had the impression that the seniority, academic background, and credentials of adjunct instructors were not valued fairly by the institution. Faculty's individual talents, skills, and history of success in academia seemed to be taken for granted. According to respondents, this issue was related to the fact that no one in management had taken the time to get to know them individually or provide them with customized treatment. The overall perception was that an adjunct instructor was a non-entity within the faculty body and was not well known to management.

There was also a distinct impression among many adjuncts that if someone in management contacted them regarding their performance, usually it was only to discuss a problem and not a situation in which the instructor deserved praise. Ng (2006) acknowledges how challenging it can be to provide performance evaluations for virtual workers. Nevertheless, managers must "provide clear descriptions of performance measures, evaluate and provide feedback regularly" (Issues for the Organization, Remote Management section, \ 2).

Levinson (2005) contends that in order to retain online adjunct faculty, institutions must put significant effort into ample and frequent communication. Often, long periods of time pass without adjuncts having any awareness of events and news regarding the institution they teach for. Keeping workers informed and providing feedback on their performance is critical to reduce feelings of insecurity and to promote self-esteem (Conner, 2003).

Although the results of this research suggests there are many issues leading to adjunct faculty's lack of satisfaction, including apparent shortcomings in leadership beyond the scope of this study, there were also positive comments, particularly about the high-quality technology employed by the university in its learning management systems. Indeed, some instructors expressed the opinion that, despite their dissatisfaction with the way they were treated and their feelings of isolation, the institution's state-of-the-art course platform was reason enough to remain part of the adjunct faculty. Interestingly, the same respondents often offered suggestions for improvement, for instance, the creation of social networking channels through which faculty could exchange all kinds of ideas, including those not necessarily of an academic nature. 
Many interviewees favored creating opportunities to increase knowledge or skills through study, travel, research, seminars, workshops, or courses, as well as social events and other activities aimed at creating a stronger sense of community. All participants appeared to unanimously agree that such events would be helpful for instructors to bond and learn from one another.

Although the desire for more frequent opportunities for socialization with peers and administrators was constant, a great number of adjuncts noted an urgent need for faculty and management to exchange ideas, regardless of how this was achieved (i.e., whether it happened face-to-face or via the Internet). Nevertheless, in advocating strongly for meeting other faculty in person, some instructors talked about the domino effect that this action could have: face-to-face meetings would nurture better communication among faculty and between faculty and management. This in turn would allow instructors to develop their skills more quickly and efficiently, which would benefit their students. And when students enjoyed a successful learning experience, they would tell friends and family, which would enhance the school's reputation and attract more talented students and faculty.

Even so, a number of participants stated that face-to-face meetings for online faculty were not essential for delivering quality services to students. However, they acknowledged that such meetings could yield many benefits, including a heightened sense of affiliation, community, camaraderie, and even motivation on the job.

These findings held the promise of giving this school's management-and presumably administrators at other online institutions as well—solid insights that could improve relationships with faculty members and ultimately benefit students. Administrators and instructors presented similar views regarding the issues raised. However, adjuncts seemed more focused on the current reality in their work situation, whereas management-except in a very few circumstances - spoke about ideal practices for faculty retention and not necessarily about what they saw happening at present. Management's mere understanding of what constitutes best practices does not necessarily translate into an incentive for faculty to remain attached to the institution. As discussed in the review of literature, when educational institutions increasingly make use of adjuncts, they must strive to attract and retain the best instructors in order to perform well against the competition. School administrators must go beyond good intentions, and listening to what adjunct faculty members have to say could help their organizations become employers of choice.

With respect to management's views on the question of gathering faculty members together, once again there was clear agreement that this type of meeting would be of great value for all participants and ultimately for the institution as a whole. However, university administrators were concerned about the costs involved in such an undertaking.

In addition, management seemed to recognize the value of regular communication with and among faculty; however, there is an apparent discrepancy between what managers consider good communication practices and faculty's perception. Some administrators seemed resigned to the idea that the school will never satisfy everyone's needs, given that individual faculty members have various preferences and life/work circumstances. 
However, the discrepancy in perceptions between faculty and administrators was particularly striking when one of the leaders, responding to a question on what could be done to strengthen adjuncts' sense of affiliation with the university, replied, "This question assumes that there is a level of mistrust between the adjuncts and the administration. If there is, I am not aware of it.”

\section{Conclusions and Recommendations}

From the analysis of completed questionnaires and telephone interview recordings, it was obvious that participants placed particular emphasis on the need for constant and clear communication between administrators and faculty members, on the improvement of recognition practices, and on the creation of more opportunities to learn from other members of the university community. Of those adjuncts who took part in the study, most expressed a strong need to become better informed on a range of institutional matters. It is clear that when administrators do not communicate often with adjunct faculty and fail to provide constant updates on the institution's management priorities, a sense of isolation increases among these instructors. Feelings of job insecurity tend to escalate as instructors are not sure whether the school is in a position to continue giving them teaching assignments. This in turn can make faculty members restless and inclined to pursue teaching opportunities elsewhere.

Issues of communication go beyond the perceived lack of feedback adjuncts get from management. In fact, a situation that seems to require even more attention is the absence of events that connect faculty members with one another. In the view of the instructors interviewed, learning from their peers' knowledge and experience would provide inspiration that could make them better teachers.

This investigation also provided insights into the value that these instructors gave to stable and reliable technology, which was their main channel of communication with students. Adjuncts seemed to be primarily interested in serving their students well; they counted on a state-of-the-art course management system to help them do their job effectively. An intuitive and reliable system, such as the one deployed by the university, allowed them to dedicate their time to teaching students instead of having to deal with course navigation and technical issues, a typical drawback of platforms that are not well designed.

All of the suggestions offered by instructors revolved around the need for clear, frequent, and wide-ranging communication. Many suggested that face-to-face gatherings of faculty would allow better interaction. It appears, however, that regardless of the channels people choose for communicating with one another, that is, via technology or face-to-face, management must create opportunities for all stakeholders to share their ideas regarding the ongoing improvement of the institution's services and reputation. This in turn will provide students with a more positive and fulfilling experience.

Although teleworkers in general experience a sense of disconnection from the workplace, there seems to be an underlying reason for adjuncts' frustration that is unique to the academic 
environment. Isolation from the institution and from their peers means that instructors lack a significant opportunity to develop their skills in order to better serve their students. Indeed, the desire to better serve students' needs was an important source of motivation for all interviewees. It appears that the ultimate goal of adjunct faculty who crave more contact with administrators and one another is to become better educators in order to give their students a more fulfilling learning experience. They want to be more informed on institutional issues so they can utilize that awareness to enable successful learning. They want to learn about technology developments so they can optimize their use of the online platform to connect with students. They want feedback on their performance so they can make the necessary improvements in their teaching approach. They want their value recognized so they can share with others their individual insights and contributions to the teaching profession.

In short, improving communication would likely satisfy an intrinsic need among the university's adjunct instructors to make a positive difference in their students' lives. Apparently, a common goal for all study participants was to connect with other faculty members so they could learn from one another's knowledge and firsthand experience. Specifically regarding the main question posed by this study, most adjuncts agreed that having occasional opportunities to meet their peers and administrators face-to-face would allow them to develop their skills in a more effective, efficient, inspiring, and indeed pleasant manner. Many envisioned benefiting from lessons that current technology does not allow them to gain. Connecting directly with colleagues could motivate them to continue discussions through the school's online Centre for Teaching and Learning forum and via email, because many professionals feel more comfortable contacting people they have met in person.

Based on their responses, it appears that adjuncts' primary allegiance is to their students rather than to the institution. The school merely serves as the means for these instructors to satisfy their love of teaching. When asked whether they felt their loyalty to the institution would increase after meeting with colleagues in person, many stated clearly that it would not; their loyalty lay, first and foremost, with their students. Similarly, most respondents expressed the view that their motivation on the job would be unaffected by face-to-face meetings. They remained motivated to give their students thoughtful attention and guidance even if their feelings toward the institution were not positive.

Where adjunct faculty felt face-to-face meetings would have an impact was on their sense of affiliation and collegiality. In their comments, instructors stressed that such gatherings would strengthen their bond with the institution and its stakeholders considerably. By getting to know others in the university community better, adjunct faculty members believed they would gain a greater sense of team spirit, welcoming the guidance and experience of others as they worked to improve their own performance as educators.

The overall conclusion one can draw from this research, therefore, is that the absence of face-toface meetings apparently does not decrease faculty's loyalty and motivation. However, the presence of such events is likely to increase loyalty and motivation for the simple reason that these meetings would allow instructors to enrich their skills and consequently serve their 
students better, which most adjuncts identify as the ultimate object of their commitment. If the school enables faculty to enrich their own academic life and thereby become better teachers by arranging face-to-face meetings, then the sense of loyalty that instructors feel toward their students will presumably extend, by virtue of its intermediary role, to the institution as well. 


\section{References}

Abowd, P. (2008). Part-time professors: Little pay, no pensions, no health care, no seniority, now organizing unions. Truth Out. Retrieved from http://www.truthout.org/issues_06/031008LA.shtml

Anderson, E. L. (2002). The new professorate: Characteristics, contributions, and compensation. Retrieved from ERIC (Education Resources Information Center) Document Reproduction Service, No. ED478300.

Bergum, S. (2007). What has happened to telework? Failure, diffusion or modification? The Journal of E-working, $1 . \quad$ Retrieved from http://64.233.167.104/search?q=cache:n42r138_BcQJ:www.merlien.org/oj/index.php/JO E/article/view/2/2+"What+has+happened+to+telework\%3F"\&hl=en\&ct=clnk\&cd=1\&cli ent=safari

Brignall, T. W. III, \& Van Valey, T. (2005). The impact of Internet communications on social interaction. Sociological Spectrum, 25(3). Retrieved from InformaWorld database.

Conner, D. S. (2003). Social comparison in virtual work environments: An examination of contemporary referent selection. Journal of Occupational and Organizational Psychology, 76, 133-147. Retrieved from ProQuest database.

Cummings, S., Heeks, R., \& Huysman, M. (2008). Knowledge and learning in online networks in development: A social-capital perspective. Development in Practice, 16(6). Retrieved from InformaWorld database.

Edwards, A. P., \& Shepherd, G. J. (2007). An investigation of the relationship between implicit personal theories of communication and community behavior. Communication Studies, 58(4). Retrieved from InformaWorld database.

Fouche, I. (2006). A multi-island situation without the ocean: Tutors' perceptions about working in isolation from colleagues. International Review of Research in Open and Distance Learning, $\quad 7(2)$. Retrieved from http://www.irrodl.org/index.php/irrodl/article/view/295/640

Fukuyama, F. (1995). Trust: The social virtues and the creation of prosperity (1st ed.). New York: Free Press.

Gaillard-Kenney, S. (2006). Adjunct faculty in distance education: What program managers should know. Distance Learning, 3(1). Retrieved from ProQuest Education Journals database. 
Golden, T. D. (2006). The role of relationships in understanding telecommuter satisfaction. Journal of Organizational Behavior, 7(2). Retrieved from http://www.irrodl.org/index.php/irrodl/rt/metadata/299/639

Gordon, M. (2003). Part-time faculty in community colleges: The jury is still out. Retrieved from ERIC Document Reproduction Service, No. ED472020.

Helms, M. M., \& Raiszadeh, F. M. E. (2002). Virtual offices: Understanding and managing what you cannot see. Work Study, 51(5). Retrieved from Ingenta Connect database.

Levinson, D. L., (2005). What do adjunct faculty want? Community College Week 18(5). Retrieved from EBSCOhost database.

Ludlow, J. (1998). Priorities and power: Adjuncts in the academy. Thought \& Action, 2. Retrieved from http://www.nea.org/home/33216.htm

Marshall, G. W., Michaels, C. E., \& Mulki, J. P. (2007). Workplace isolation: Exploring the construct and its measurement. Psychology \& Marketing, 24(3). Retrieved from InterScience Wiley database.

McGuire, J. (1993). Part time faculty: Partners in excellence. Leadership Abstracts, 6(6). Retrieved from ERIC Document Reproduction Service, No. ED367429

Merriman, K. K., Schmidt, S. M., \& Dunlap-Hinkler, D. (2007). Profiling virtual employees: The impact of managing virtually. Journal of Leadership \& Organizational Studies, 14(1). Retrieved from Sage Journals Online database.

Morgan, S. J., \& Symon, G. (2002). Computer-mediated communication and remote management: Integration or isolation? Social Science Computer Review, 20(3). Retrieved from Sage Journals Online database.

Morse, J. M. (2000). Determining sample size. Qualitative Health Research, 10(3). Retrieved from Sage Journals Online database.

Nelson, B. (2002). Managing virtual employees. In Nelson motivation online store. Retrieved from http://nelson-motivation.stores.yahoo.net/maviem.html

Ng, C. F. (2006). Academics telecommuting in open and distance education universities: Issues, challenges, and opportunities. International Review of Research in Open and Distance Learning, $\quad 7(2)$. $\quad$ Retrieved from http://www.irrodl.org/index.php/irrodl/article/view/300/632

Putnam, R. D. (2000). Bowling alone: The collapse and revival of American community (1st ed.). New York: Simon \& Schuster. 
Roberts, C., Thomas, M., McFadden, A. T., \& Jacobs, J. (2006). Leading online learning through collaboration. Journal of Online Learning and Teaching, 2(3). Retrieved from http://jolt.merlot.org/vol2no3/roberts.htm

Schnitzer, M., \& Crosby, L. S. (2003). Recruitment and development of online adjunct instructors. Retrieved from http://www.westga.edu/ distance/ojdla/summer62/crosby_schnitzer62.html

Shellenbarger, S. (2008). Some companies rethink the telecommuting trend. The Wall Street Journal. Retrieved from http://online.wsj.com/article/SB120416669485798807.html

Thomson, B. S. (n.d.). Qualitative research: Grounded theory-sample size and validity. Retrieved from http://www.buseco.monash.edu.au/research/studentdoc s/mgt.pdf.

Unger, D. N. S. (1995). Academic apartheid: The predicament of part-time faculty. The NEA Higher Education-Thought and Action JOURNAL, 61. Retrieved from http://www2.nea.org/he/heta00/f00p61.pdf

Yu, C. \& Young, M. (2008). The virtual group identification process: A virtual educational community case. CyberPsychology \& Behavior, 11(1), 87-90. Retrieved from EBSCOhost database.

\section{Athabasca University $\mathbf{A}$}

